\title{
Space Vector Modulated Direct Torque Control of IPMSM Drive
}

\author{
Dr. E.V.C.Sekhara Rao \\ Asst. Professor, Department of EEE, CBIT, Hyderabad, Telangana State.
}

\begin{abstract}
The Direct Torque Control (DTC) theory has achieved great success in the control of induction motor. Many attempts have been made to implement the idea of DTC of induction motor to permanent magnet synchronous machine since 1990's. The advantages of DTC of permanent magnet synchronous machine drives include less machine parameter dependence, simpler implementation and quicker dynamic torque response. The work of this paper is to study, evaluate and compare the various techniques of the DTC applied to the IPMSM through simulations. The simulations were carried out using Matlab/Simulink simulation package. Evaluation was made based on the drive performance, which includes steady state and dynamic torque and flux responses.
\end{abstract}

Keywords: Space Vector Modulation, Direct Torque Control, Interior Permanent magnet Synchronous Motor, Matlab.

\section{INTRODUCTION}

The original concept of DTC was proposed by Takahashi and Noguchi in 1986 for application in Induction Motors. Their idea was to control the stator flux linkage and the torque directly, not via controlling the stator current. This was accomplished by controlling the power switches directly using the outputs of hysteresis comparators for the torque and the modulus of the stator flux linkage and selecting an appropriate voltage vector from a predefined switching table. The table was called the "optimum switching table". The measurement of the rotor angle was not used.

A similar control was proposed by Depenbrock (1987). At first, Takahashi and Noguchi did not give any name to their new control principle. In a later paper by Takahasi and Ohmori (1987) the control system was named the Direct Torque Control, DTC. Depenbrock called his control method Direct Self Control (DSC). Tiitenen et al discussed the first industrial application of the DTC. After that, number of papers on the DTC has grown tremendously on different aspects of the DTC for asynchronous motors. In recent years there has been interest to apply the DTC to permanent magnet synchronous motors.

L.Zhong et al discussed the implementation of DTC in PMSM Drives. In 1998, Rahman et al proposed a DTC scheme for a wide speed range operation of an IPMSM drive. The proposed scheme possesses some attractive features compared to the conventional current-controlled drives like field oriented control (FOC). To reduce the torque ripples, Sun et al proposed a fuzzy logic algorithm to refine the selection of the voltage vectors.In 2004; Tang et al proposed a DTC-SVM control schemes for the IPM featuring almost fixed switching frequency with low ripple in torque and flux [1].

Later in 2006, Jun Zhang et al proposed a new scheme to DTC for an IPM drive, which provided a variable option for the improvement of DTC-SVM controlled IPMSM [2]. Today, the DTC has become an accepted control method beside the field oriented control.

The objectives of this paper are to simulate the conventional switching table based DTC, cascade structure of DTC-SVM and parallel structure of DTC-SVM schemes for IPMSM drive using Matlab/Simulink and to reduce the torque and flux ripples and maintain constant inverter switching frequency in DTC-SVM schemes for IPMSM drive when compared to the classical ST-DTC.

\section{MODELING OF PM SNCHRONOUS MOTOR}

In this project an Interior type Permanent Magnet Synchronous Motor (IPMSM) is used for the analysis. The development of those models is under below assumptions as [3]:

- Three-phase motor is symmetrical,

- Only a fundamental harmonic of the magneto motive force (MMF) is taken in to account,

- The spatially distributed stator and rotor windings are replaced by a concentrated coil,

- An anisotropy effects, magnetic saturation, iron loses and eddy currents are not taken into considerations,

- The coil resistances and reactances are taken to be constant,

- In many cases, especially when it is considered steady state, the currents and voltages are assumed to be sinusoidal,

- Thermal effect for permanent magnets is omitted.

In space vector representation the instantaneous value of a three-phase system $\mathrm{K}_{A}, \mathrm{~K}_{B}, \mathrm{~K}_{C}$ (such as currents, voltages and flux linkages) can be replaced by one resultant vector called the space vector,

$$
\mathrm{K}=\frac{2}{3}\left[1 \cdot \mathrm{K}_{\mathrm{A}}+a \cdot \mathrm{K}_{\mathrm{B}}+a^{2} \cdot \mathrm{K}_{\mathrm{C}}\right]
$$

Where $1, a, a^{2}$ are complex vectors defined as

$a=-\frac{1}{2}+j \frac{\sqrt{3}}{2}$ and $a^{2}=-\frac{1}{2}-j \frac{\sqrt{3}}{2}$ 
$\frac{2}{3}$ - normalization factor.

\section{1 Voltage and current equations}

For idealized motor (Fig.1), the following equations of the instantaneous stator phase voltages can be written [3]:

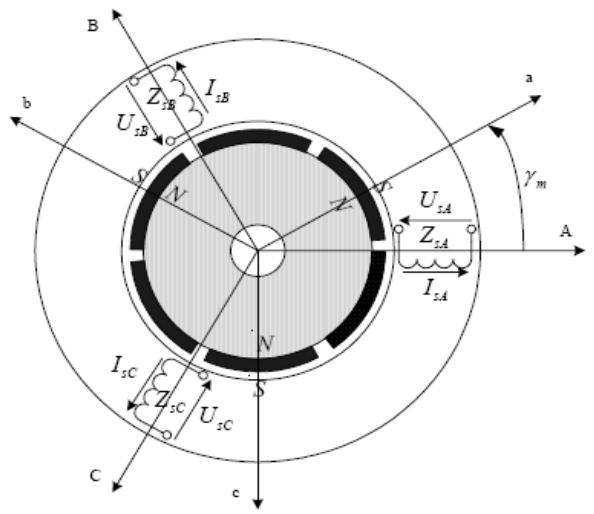

Fig. 1 Layout and symbols for three-phase PMSM electric motor windings

$$
\begin{aligned}
& V_{s A}=\mathrm{R}_{\mathrm{sA}} I_{s A}+\frac{d \lambda_{s A}}{d t} \\
& V_{s B}=\mathrm{R}_{\mathrm{sB}} I_{s B}+\frac{d \lambda_{s B}}{d t} \\
& V_{s C}=\mathrm{R}_{\mathrm{sC}} I_{s C}+\frac{d \lambda_{s C}}{d t}
\end{aligned}
$$

Where $V_{S A}, V_{s B}, V_{s C}$ are the instantaneous stator voltage values, $I_{s A}, I_{s B}, I_{s C}$ are instantaneous values of the current, $\mathrm{R}_{\mathrm{s}}=\mathrm{R}_{\mathrm{sA}}=\mathrm{R}_{\mathrm{sB}}=\mathrm{R}_{\mathrm{SC}}$ is the resistance of the stator windings, and $\lambda_{\mathrm{SA}}, \lambda_{\mathrm{SB}}, \lambda_{\mathrm{SC}}$ are magnetic flux linkages of stator windings $A, B$ and $C$, respectively.

Using the space vector theory to voltage equations we can written in vector form

$$
V_{s A B C}=\mathrm{R}_{\mathrm{sABC}} I_{S A B C}+\frac{d \lambda_{s A B C}}{d t}
$$

Where, $V_{S A B C}=\frac{2}{3}\left(V_{S A}+\mathrm{a} V_{s B}+\mathrm{a}^{2} V_{S C}\right)$,

$$
\begin{aligned}
I_{s A B C} & =\frac{2}{3}\left(I_{s A}+\mathrm{a} I_{s B}+\mathrm{a}^{2} I_{s C}\right), \\
\lambda_{S A B C} & =\frac{2}{3}\left(\lambda_{s A}+\mathrm{a} \lambda_{s B}+\mathrm{a}^{2} \lambda_{S C}\right)
\end{aligned}
$$

are the stator voltages, currents and flux space vectors, respectively.

The stator winding flux consists of rotor flux and stator flux linkages:

Where,

$$
\lambda_{s A B C}=\lambda_{A B C(s)}+\lambda_{A B C(r)}
$$

$$
\lambda_{A B C(s)}=\left[\begin{array}{ccc}
L_{s A} & M_{s A B} & M_{s A C} \\
M_{s B A} & L_{s B} & M_{s B C} \\
M_{s C A} & M_{s C B} & L_{s C}
\end{array}\right]\left[\begin{array}{l}
I_{s A} \\
I_{s B} \\
I_{s C}
\end{array}\right]
$$

$$
\lambda_{A B C(r)}=\lambda_{P M}\left[\begin{array}{c}
\cos \theta_{r} \\
\cos \left(\theta_{r}-\frac{2 \pi}{3}\right) \\
\cos \left(\theta_{r}+\frac{2 \pi}{3}\right)
\end{array}\right]
$$

and, $\theta_{\mathrm{r}}$ is electrical rotor position. Mechanical rotor position is defined as:

$$
\gamma_{m}=\frac{\theta_{r}}{p_{b}}
$$

Where: $p_{b}$ - number of pole pairs, $\gamma_{m}$ - mechanical position

In equation (2.5) $L_{s A}$ is the self-inductance of phase $A$ winding, $M_{S A B}$ and $M_{S A C}$ are the mutual inductances between $A$ and $B$ phase, $A$ and $C$ phase, respectively. For self and mutual inductances of $B$ and $C$ phase the same notations are used. In (2.6), $\lambda_{P M}$ is the amplitude of the flux linkages established by the permanent magnet on the rotor. The inductances are described below.

Due to the rotor saliency in IPMSM the air gap is not uniform and therefore, the self and mutual inductances of stator windings are a function of the rotor position. The derivation of these rotor position dependent inductances is available in details in [ $4 \& 5]$. The results are summarized here as follows:

The stator winding self-inductances are

$$
\begin{gathered}
L_{s A}=L_{l s}+L_{A}-L_{B} \cos 2 \theta_{\mathrm{r}}(8 \mathrm{a}) \\
L_{s B}=L_{l s}+L_{A}-L_{B} \cos 2\left(\theta_{\mathrm{r}}-\frac{2 \pi}{3}\right)(8 \mathrm{~b}) \\
L_{s C}=L_{l s}+L_{A}-L_{B} \cos 2\left(\theta_{\mathrm{r}}+\frac{2 \pi}{3}\right)(8 \mathrm{c})
\end{gathered}
$$

where, $L_{l s}$ is stator-winding leakage inductance and $L_{A}, L_{B}$ are given by

$$
\begin{gathered}
L_{A}=\left(\frac{m_{s}}{2}\right)^{2} \pi \mu_{\mathrm{o}} r l \varepsilon_{1}(9 \mathrm{a}) \\
L_{B}=\frac{1}{2}\left(\frac{m_{s}}{2}\right)^{2} \pi \mu_{\mathrm{o}} r l \varepsilon_{2}(9 \mathrm{~b})
\end{gathered}
$$

Where, $m_{s}$ is number of turns of each phase winding, $r$ is radius, which is from center of machine to the inside circumference of the stator, and $l$ is the axial length of the air gap of the machine, $\mu_{\mathrm{o}}$ is permeability of the air, $\varepsilon_{l}$ and $\varepsilon_{2}$ are defined as:

$$
\begin{aligned}
& \varepsilon_{1}=\frac{1}{2}\left(\frac{1}{g_{\text {min }}}+\frac{1}{g_{\text {max }}}\right) \\
& \varepsilon_{2}=\frac{1}{2}\left(\frac{1}{g_{\text {min }}}-\frac{1}{g_{\text {max }}}\right)
\end{aligned}
$$

Where, $\mathrm{g}_{\min }$ is minimum air gap length and $\mathrm{g}_{\max }$ is maximum air gap length. 
The mutual inductances between stator phases are:

$$
\begin{gathered}
M_{S A B}=M_{S B A}=-\frac{1}{2} L_{A}-L_{B} \cos 2\left(\theta_{\mathrm{r}}-\frac{\pi}{3}\right) \\
M_{S A C}=M_{S C A}=-\frac{1}{2} L_{A}-L_{B} \cos 2\left(\theta_{\mathrm{r}}+\frac{\pi}{3}\right)(11 \mathrm{~b}) \\
M_{S B C}=M_{s C B}=-\frac{1}{2} L_{A}-L_{B} \cos 2\left(\theta_{\mathrm{r}}+\pi\right)= \\
-\frac{1}{2} L_{A}-L_{B} \cos 2 \theta_{\mathrm{r}}
\end{gathered}
$$

Using the space vector theory, the flux linkage space vector $\lambda_{S A B C}$ can be written as:

$\lambda_{s A B C}=\left(L_{l s}+\frac{3}{2} L_{A}\right) I_{S A B C}-\frac{3}{2} L_{B} I_{S A B C} e^{j 2 \theta r}+\lambda_{P M} e^{j \theta r}$

Where, $\quad I_{s A B C}=\frac{2}{3}\left(I_{s A}+\mathrm{a} I_{s B}+\mathrm{a}^{2} I_{S C}\right)$,

$$
I_{S A B C}{ }^{*}=\frac{2}{3}\left(I_{s A}+\mathrm{a}^{2} I_{s B}+\mathrm{a} I_{s C}\right)
$$

are the stator current space vector and conjugate stator current space vector.

Taking into account that:

$$
\begin{aligned}
& L_{d}=L_{l s}+L_{m d} \quad(13 \mathrm{a}) \\
& L_{q}=L_{l s}+L_{m q}(13 \mathrm{~b})
\end{aligned}
$$

Where, $L_{m d}=\frac{3}{2}\left(L_{A}+L_{B}\right), L_{m q}=\frac{3}{2}\left(L_{A}-L_{B}\right)$ are d and $\mathrm{q}$ magnetizing inductances and are defined as [5].

Finally, equation (2.12) comes as:

$$
\lambda_{s A B C}=\left(\frac{L_{d}+L_{q}}{2}\right) I_{S A B C}-\left(\frac{L_{q}-L_{d}}{2}\right) I_{s A B C}{ }^{*} e^{j 2 \theta r}+\lambda_{P M}
$$

where, $L_{d}, L_{q}$ are $\mathrm{d}$ and $\mathrm{q}$ inductances.

Space vector form of machine equations $(2.3,2.14)$ becomes more compact, but the rotor position dependent parameters still exist in that form of expressions for the stator flux linkage space vector. Therefore, the space vector model is still not simple to use for the analysis. A simplification can be made if the space vector model is referred to a suitably selected rotating frame.

Figure 2 shows axes of reference for the three-stator phase $A, B, C$. It also shows a rotating set of $x, y$ axes, where the angle $\theta_{K}$ is position of $x$-axis in respect to the stator $A$ phase axis. Variables along the $A, B$ and $C$ axes can be referred to the $x$ and $y$ axes by the expression:

$$
\left[\begin{array}{l}
K_{x} \\
K_{y}
\end{array}\right]=\frac{2}{3}\left[\begin{array}{ccc}
\cos \theta_{K} & \cos \left(\theta_{K}-2 \pi / 3\right) & \cos \left(\theta_{K}+2 \pi / 3\right) \\
-\sin \theta_{K} & -\sin \left(\theta_{K}-2 \pi / 3\right) & -\sin \left(\theta_{K}+2 \pi / 3\right)
\end{array}\right]\left[\begin{array}{l}
K_{A} \\
K_{B} \\
K_{C}
\end{array}\right]
$$

Finally, the space vector in general rotating frame can be written as:

$$
K_{s A B C}=\left|\mathrm{K}_{K}\right|\left(\cos \theta_{K}+j \sin \theta_{K}\right)=\left|\mathrm{K}_{K}\right| e^{j \theta_{\mathrm{K}}}
$$

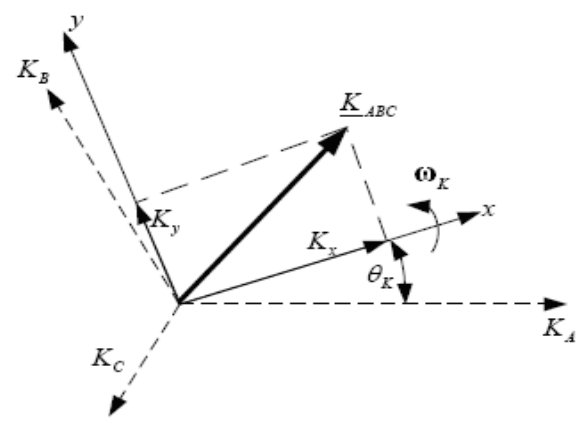

Fig. 2 Stator fixed three phase axes (A, B, C) and general rotating reference frame $(\mathrm{x}, \mathrm{y})$

In this case the voltage equation (3) using (16) can be written as:

$$
V_{s K} e^{j \theta_{\mathrm{K}}}=R_{s} I_{s K} e^{j \theta_{\mathrm{K}}}+\frac{d}{d t}\left(\lambda_{s K} e^{j \theta_{K}}\right)
$$

Using chain rule, equation (17) and divided by term $e^{j \theta_{\mathrm{K}}}$ can be written as:

$$
V_{s K}=R_{s} I_{s K}+\frac{d \lambda_{s K}}{d t}+j \omega_{K} \lambda_{s K}
$$

Where $V_{s K}, I_{s K}, \lambda_{s K}$ is the stator voltage, current and flux space vector in general rotating frame.

Making similar arrangement like for the voltage equation the flux linkage vector in general reference frame can be expressed as:

$$
\begin{gathered}
\lambda_{s K}=\left(\frac{L_{d}+L_{q}}{2}\right) I_{s K}-\left(\frac{L_{q}-L_{d}}{2}\right) I_{s K}{ }^{*} e^{j 2\left(\theta_{r}-\theta_{\mathrm{K}}\right)}+\lambda_{P M} \\
e^{j\left(\theta_{r}-\theta_{\mathrm{K}}\right)}
\end{gathered}
$$

Stator fixed system $(\alpha, \beta)$

Taking the angular speed of the reference frame to be $\omega_{K}=$ 0 and $\theta_{K}=0$, the set of synchronous machine vector equations (18) and (19) may be written as:

$$
\begin{gathered}
V_{s \alpha \beta}=R_{s} I_{s \alpha \beta}+\frac{d \lambda_{s \alpha \beta}}{d t}(20) \\
\lambda_{s \alpha \beta}=\left(\frac{L_{d}+L_{q}}{2}\right) I_{s \alpha \beta}-\left(\frac{L_{q}-L_{d}}{2}\right) I_{s \alpha \beta}{ }^{*} e^{j 2 \theta r}+\lambda_{P M} e^{j \theta r}
\end{gathered}
$$

Substituting the following expressions $V_{s \alpha \beta}=V_{s \alpha}+j V_{s \beta}$, $I_{s \alpha \beta}=I_{s \alpha}+\mathrm{j} I_{s \beta}, \lambda_{s \alpha \beta}=\lambda_{\mathrm{s} \alpha}+j \lambda_{s \beta}$ in to above equations and splitting in to real and imaginary parts one can obtain the scalar form of the machine equations in stationary $\alpha, \beta$ reference frame:

$$
\begin{gathered}
V_{s \alpha}=R_{s} I_{s \alpha}+\frac{d \lambda_{s \alpha}}{d t}(22) \\
V_{s \beta}=R_{s} I_{s \beta}+\frac{d \lambda_{s \beta}}{d t}(22 \mathrm{~b}) \\
\lambda_{s \alpha}=\left(\frac{L_{d}+L_{q}}{2}-\frac{L_{q}-L_{d}}{2} \cos 2 \theta_{\mathrm{r}}\right) I_{s \alpha}-\left(\frac{L_{q}-L_{d}}{2}\right) \sin 2 \theta_{\mathrm{r}} I_{s \beta}+\lambda_{P M} \\
\lambda_{s \beta}=-\left(\frac{L_{q}-L_{d}}{2}\right) \sin 2 \theta_{\mathrm{r}} I_{s \alpha}+\left[\left(\frac{L_{d}+L_{q}}{2}\right)+\left(\frac{L_{q}-L_{d}}{2}\right) \cos 2 \theta_{\mathrm{r}}\right] I_{s \beta} \\
+\lambda_{P M} \sin \theta_{\mathrm{r}}
\end{gathered}
$$


Note, that in the flux-current equations (23a and b) still we can observe that value of inductances depends on rotor position $\theta_{\mathrm{r}}$.

\section{SPACE VECTOR PULSE WIDTH MODULATION}

Due to the advancement in the field of power device technology and the development of large integrated circuits in the recent years have paved way for the modern fast switching PWM technique for DC-AC power conversion. Because of advances in solid state power devices and microprocessor, PWM inverters are becoming more and more popular in today's motor drives. PWM inverters make it possible to control both the frequency and magnitude of the voltage and current applied to a motor. As a result, PWM inverter powered motor drives offer better efficiency and higher performances compared to fixed frequency motor drives [6].

Nowadays there are different PWM techniques are available. The space vector control is one of the most widely used PWM techniques for three-phase voltage source inverters (VSI) in applications such as control of induction and permanent magnet synchronous motors. It is based on the decomposition of any voltage/field (as may be the case) into a combination of the basic vectors. Any given voltage or field phasor can be generated by switching the devices of the bridge as per the duty ratios calculated. The exact sequence of switching is decided on the basis of various other considerations such as minimizing the switching frequency, total harmonic distortion etc. The circuit model of a typical three-phase voltage source PWM inverter is shown in Fig. $3 . S_{1}$ to $S_{6}$ are the six power switches that shape the output, which are controlled by the switching variables A, A', B, B', C and $\mathrm{C}^{\prime}$. When an upper transistor is switched on, i.e., when $\mathrm{A}$, $\mathrm{B}$ or $\mathrm{C}$ is 1 , the corresponding lower transistor is switched off, i.e., the corresponding $\mathrm{A}^{\prime}, \mathrm{B}^{\prime}$ or $\mathrm{C}^{\prime}$ is 0 . Therefore, the on and off states of the upper transistors $S_{1}, S_{3}$ and $S_{5}$ can be used to determine the output voltage.

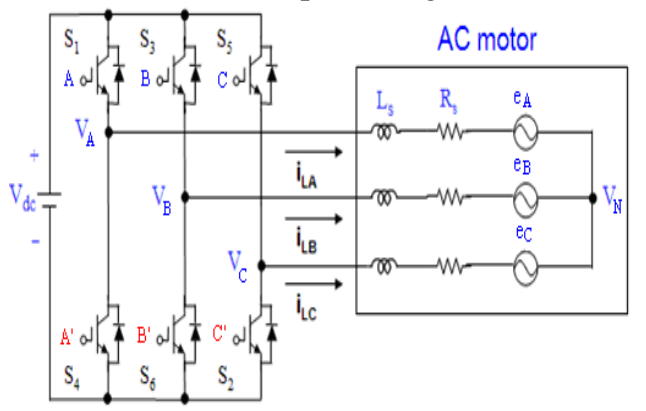

Fig. 3 Three-phase voltage source PWM Inverter

The relationship between the switching variable vector [A, $\mathrm{B}, \mathrm{C}]^{\mathrm{t}}$ and the line-to-line voltage vector $\left[V_{A B} V_{B C} V_{C A}\right]^{\mathrm{t}}$ is as follows:

$$
\left[\begin{array}{l}
V_{A B} \\
V_{B C} \\
V_{C A}
\end{array}\right]=V_{d c}\left[\begin{array}{ccc}
1 & -1 & 0 \\
0 & 1 & -1 \\
-1 & 0 & 0
\end{array}\right]\left[\begin{array}{l}
A \\
B \\
C
\end{array}\right]
$$

Also, the relationship between the switching variable vector $[\mathrm{A}, \mathrm{B}, \mathrm{C}]^{\mathrm{t}}$ and the phase voltage vector $\left[V_{A} V_{B} V_{C}\right]^{\mathrm{t}}$ can be expressed as below.

$$
\left[\begin{array}{l}
V_{A N} \\
V_{B N} \\
V_{C N}
\end{array}\right]=\frac{V_{d c}}{3}\left[\begin{array}{ccc}
2 & -1 & -1 \\
-1 & 2 & -1 \\
-1 & -1 & 2
\end{array}\right]\left[\begin{array}{l}
A \\
B \\
C
\end{array}\right] \text { (25) }
$$

Because of the constraint that the input lines must never be shorted and the output current must always be continuous a voltage source inverter can assume only eight distinct topologies. These topologies are shown in Fig. 4. Six out of these eight topologies produce a nonzero output voltage and are known as non-zero switching states and the remaining two topologies produce zero output voltage and are known as zero switching states.
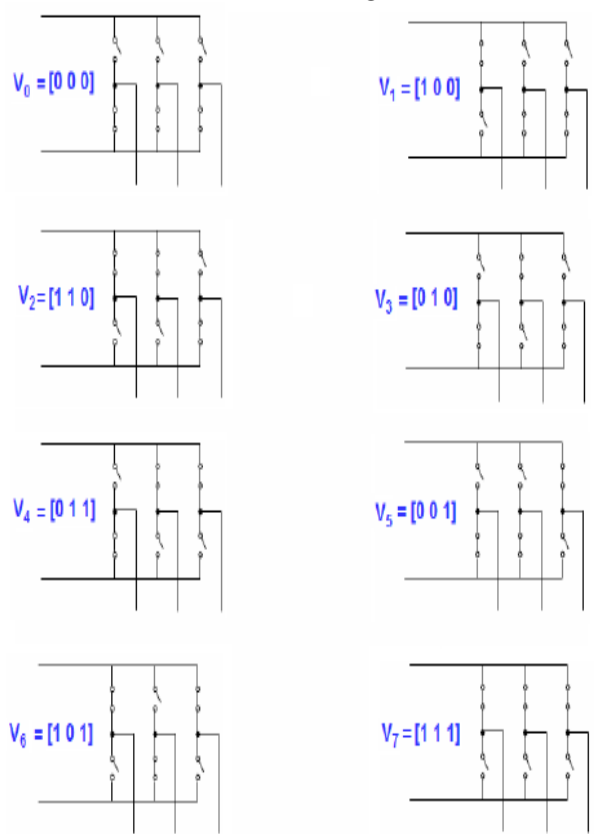

Fig. 4 Eight switching state topologies of a voltage source inverter.

Table 1 Switching vectors, phase voltages and output line to line voltages

\begin{tabular}{|c|c|c|c|c|c|c|c|c|c|}
\hline \multirow{2}{*}{$\begin{array}{l}\text { Voltage } \\
\text { vectors }\end{array}$} & \multicolumn{3}{|c|}{$\begin{array}{c}\text { Switching } \\
\text { vectors }\end{array}$} & \multicolumn{3}{c|}{$\begin{array}{c}\text { Line to neutral } \\
\text { voltage }\end{array}$} & \multicolumn{3}{c|}{$\begin{array}{l}\text { Line to line } \\
\text { voltage }\end{array}$} \\
\cline { 2 - 10 } & $\mathrm{A}$ & $\mathrm{B}$ & $\mathrm{C}$ & $\mathrm{V}_{\mathrm{AN}}$ & $\mathrm{V}_{\mathrm{BN}}$ & $\mathrm{V}_{\mathrm{CN}}$ & $\mathrm{V}_{\mathrm{AB}}$ & $\mathrm{V}_{\mathrm{BC}}$ & $\mathrm{V}_{\mathrm{CA}}$ \\
\hline $\mathrm{V}_{0}$ & 0 & 0 & 0 & 0 & 0 & 0 & 0 & 0 & 0 \\
\hline $\mathrm{V}_{1}$ & 1 & 0 & 0 & $2 / 3$ & $-1 / 3$ & $-1 / 3$ & 1 & 0 & -1 \\
\hline $\mathrm{V}_{2}$ & 1 & 1 & 0 & $1 / 3$ & $1 / 3$ & $-2 / 3$ & 0 & 1 & -1 \\
\hline $\mathrm{V}_{3}$ & 0 & 1 & 0 & $-1 / 3$ & $2 / 3$ & $-1 / 3$ & -1 & 1 & 0 \\
\hline $\mathrm{V}_{4}$ & 0 & 1 & 1 & $-2 / 3$ & $1 / 3$ & $1 / 3$ & -1 & 0 & 1 \\
\hline $\mathrm{V}_{5}$ & 0 & 0 & 1 & $-1 / 3$ & $-1 / 3$ & $2 / 3$ & 0 & -1 & 1 \\
\hline $\mathrm{V}_{6}$ & 1 & 0 & 1 & $1 / 3$ & $-2 / 3$ & $1 / 3$ & 1 & -1 & 0 \\
\hline $\mathrm{V}_{7}$ & 1 & 1 & 1 & 0 & 0 & 0 & 0 & 0 & 0 \\
\hline
\end{tabular}

(Note that the respective voltage should be multiplied by $\left.\mathrm{V}_{\mathrm{dc}}\right)$

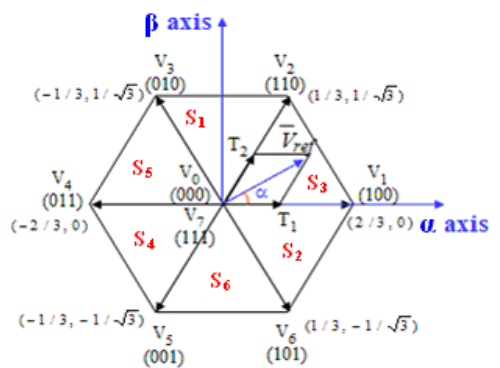

Fig. 5 Basic switching vectors and sectors 
Table $2 T_{1}$ and $T_{2}$ in all specific sectors

\begin{tabular}{|c|c|c|c|c|c|c|}
\hline & $\mathbf{S}_{\mathbf{3}}$ & $\mathbf{S}_{\mathbf{1}}$ & $\mathbf{S}_{\mathbf{5}}$ & $\mathbf{S}_{\mathbf{4}}$ & $\mathbf{S}_{\mathbf{6}}$ & $\mathbf{S}_{\mathbf{2}}$ \\
\hline $\boldsymbol{T}_{\mathbf{1}}$ & $-T_{Z}$ & $T_{Z}$ & $T_{X}$ & $-T_{X}$ & $-T_{Y}$ & $T_{Y}$ \\
\hline $\boldsymbol{T}_{\mathbf{2}}$ & $T_{X}$ & $T_{Y}$ & $-T_{Y}$ & $T_{Z}$ & $-T_{Z}$ & $-T_{X}$ \\
\hline
\end{tabular}

Table 3 Relation between sector switch operation time and duty cycle

\begin{tabular}{|c|c|c|c|c|c|c|}
\hline & $\mathrm{S}_{3}$ & $\mathrm{~S}_{1}$ & $\mathrm{~S}_{5}$ & $\mathrm{~S}_{4}$ & $\mathrm{~S}_{6}$ & $\mathrm{~S}_{2}$ \\
\hline$T_{c m 1}$ & $T a_{o n}$ & $T b_{o n}$ & $T c_{o n}$ & $T c_{o n}$ & $T b_{o n}$ & $T a_{o n}$ \\
\hline$T_{c m 2}$ & $T b_{o n}$ & $T a_{o n}$ & $T a_{o n}$ & $T b_{o n}$ & $T c_{o n}$ & $T c_{o n}$ \\
\hline$T_{c m 3}$ & $T c_{o n}$ & $T c_{o n}$ & $T b_{o n}$ & $T a_{o n}$ & $T a_{o n}$ & $T b_{o n}$ \\
\hline
\end{tabular}

\section{DIRECT TORQUE CONTROL OF IPMSM DRIVE}

Direct Torque Control (DTC) is the most advanced AC drive technology. DTC is the first technology to control the "real" motor control variables of torque and flux linkage [7, 8, $9 \& 10]$. The direct torque control was introduced in the 1980's for induction machine for torque and flux control. It was developed for PMSM in 1990's. The DTC is gaining popularity due to its simple control structure and easy implementation. This paper presents different schemes of DTC for IPMSM drive.

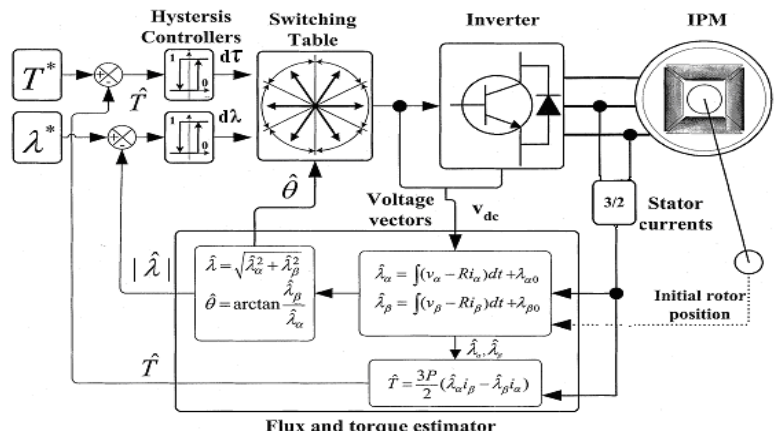

Fig. 6 Block diagram of ST-DTC for IPMSM drive

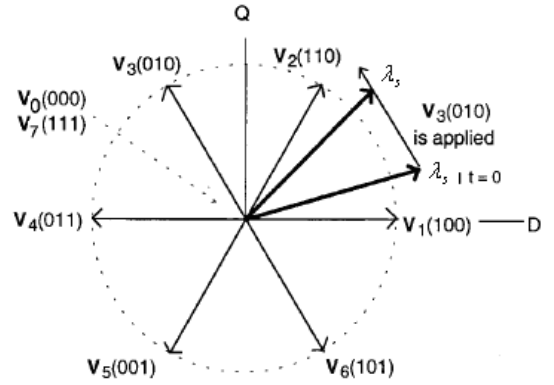

Fig. 7 The movement of the end of stator flux linkage

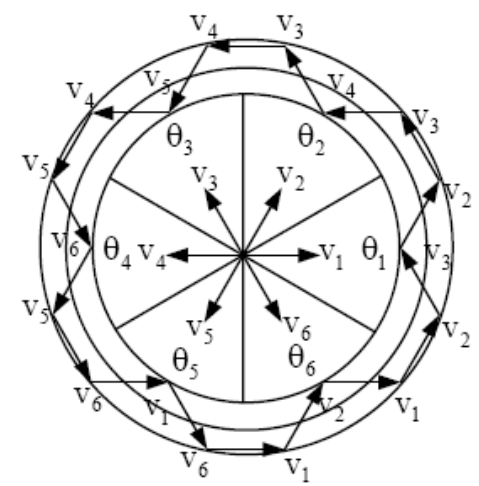

Fig. 8 The control of the stator flux linkage

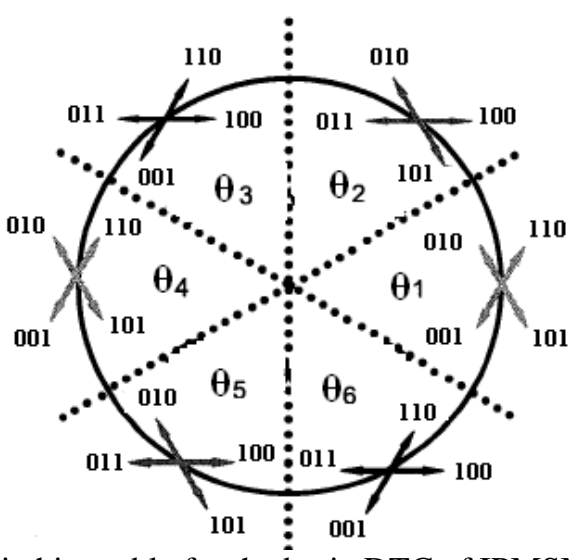

Fig. 9 Switching table for the basic DTC of IPMSM drive

Table 4 Switching table for inverter

\begin{tabular}{|c|c|c|c|c|c|c|c|}
\hline \multirow{2}{*}{$d_{\lambda s}$} & \multirow{2}{*}{$d_{T e}$} & \multicolumn{6}{|c|}{$\theta$} \\
\hline & & $\theta(1)$ & $\theta(2)$ & $\theta(3)$ & $\theta(4)$ & $\theta(5)$ & $\theta(6)$ \\
\hline \multirow{2}{*}{$\begin{array}{l}d_{\lambda s} \\
=1\end{array}$} & $\begin{array}{l}d_{T e} \\
=1\end{array}$ & $\begin{array}{c}V_{2} \\
(110)\end{array}$ & $\begin{array}{c}V_{3} \\
(010)\end{array}$ & $\begin{array}{c}\mathrm{V}_{4} \\
(011)\end{array}$ & $\begin{array}{c}\mathrm{V}_{5} \\
(001)\end{array}$ & $\begin{array}{c}\mathrm{V}_{6} \\
(101)\end{array}$ & $\begin{array}{c}V_{1} \\
(100)\end{array}$ \\
\hline & $\begin{array}{l}d_{T e} \\
=0\end{array}$ & $\begin{array}{c}V_{6} \\
(101) \\
\end{array}$ & $\begin{array}{c}V_{1} \\
(100) \\
\end{array}$ & $\begin{array}{c}V_{2} \\
(110) \\
\end{array}$ & $\begin{array}{c}\mathrm{V}_{3} \\
(010) \\
\end{array}$ & $\begin{array}{c}\mathrm{V}_{4} \\
(011) \\
\end{array}$ & $\begin{array}{c}\mathrm{V}_{5} \\
(001) \\
\end{array}$ \\
\hline \multirow{2}{*}{$\begin{array}{l}d_{\lambda s} \\
=0\end{array}$} & $\begin{array}{l}d_{T e} \\
=1\end{array}$ & $\begin{array}{c}\mathrm{V}_{3} \\
(010)\end{array}$ & $\begin{array}{c}\mathrm{V}_{4} \\
(011)\end{array}$ & $\begin{array}{c}\mathrm{V}_{5} \\
(001)\end{array}$ & $\begin{array}{c}\mathrm{V}_{6} \\
(101)\end{array}$ & $\begin{array}{c}\mathrm{V}_{1} \\
(100)\end{array}$ & $\begin{array}{c}\mathrm{V}_{2} \\
(110)\end{array}$ \\
\hline & $\begin{array}{l}d_{T e} \\
=0\end{array}$ & $\begin{array}{c}V_{5} \\
(001)\end{array}$ & $\begin{array}{c}\mathrm{V}_{6} \\
(101)\end{array}$ & $\begin{array}{c}\mathrm{V}_{1} \\
(100)\end{array}$ & $\begin{array}{c}\mathrm{V}_{2} \\
(110)\end{array}$ & $\begin{array}{c}V_{3} \\
(010)\end{array}$ & $\begin{array}{c}\mathrm{V}_{4} \\
(011)\end{array}$ \\
\hline
\end{tabular}

In Table $4, d_{\lambda s}$ and $d_{T e}$ are the outputs of the hysteresis controllers for flux linkage and torque, respectively. If $d_{\lambda s}=1$, then the actual flux linkage is smaller than the reference value and if $d_{\lambda s}=0$, then the actual flux linkage is greater than the reference value. The same is true for the torque. $\theta(1)-\theta(6)$ are the region numbers for the stator flux linkage positions.

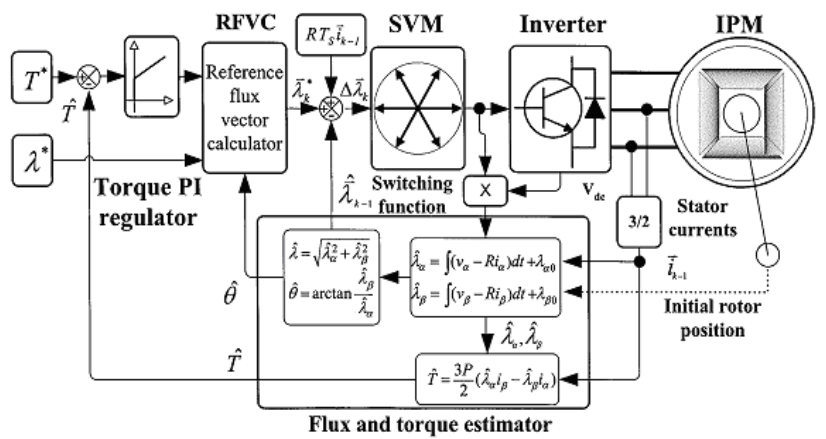

Fig. 10 Cascade structure of DTC-SVM scheme

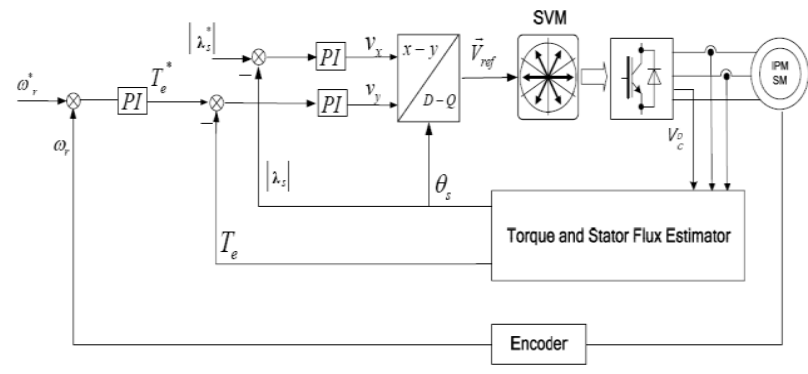

Fig. 11 Parallel structure of DTC-SVM scheme 
5.

SIMULATION AND RESULTS ANALYSIS

The Switching Table based DTC, DTC-SVM with cascade structure, and DTC-SVM with parallel structure schemes described in previous chapter have been simulated using Matlab/Simulink simulation package. All the Matlab/Simulink models were developed with the speed loop closed. The simulation models are presented and the results are discussed. The impact of different control strategies on the IPMSM are compared to each other and will be discussed in this chapter.

The steady state performances of three schemes of DTC of IPMSM drive is given in Table 5, comparing the sampling time, torque ripple and flux linkage ripple.

Table 5.5 Comparison of steady state performance of DTC schemes

\begin{tabular}{|c|c|c|c|}
\hline Scheme & $\begin{array}{c}\text { Sampling } \\
\text { time }(\mu \mathrm{s})\end{array}$ & $\begin{array}{c}\text { Torque } \\
\text { ripple } \\
(\mathrm{Nm})\end{array}$ & $\begin{array}{c}\text { Flux } \\
\text { linkage } \\
\text { ripple } \\
(\mathrm{Wb})\end{array}$ \\
\hline ST-DTC & 75 & \pm 0.5 & \pm 0.01 \\
\hline $\begin{array}{c}\text { Cascade } \\
\text { structure of } \\
\text { DTC-SVM }\end{array}$ & 150 & \pm 0.03 & \pm 0.003 \\
\hline $\begin{array}{c}\text { Parallel } \\
\text { structure of } \\
\text { DTC-SVM }\end{array}$ & 150 & \pm 0.04 & \pm 0.005 \\
\hline
\end{tabular}

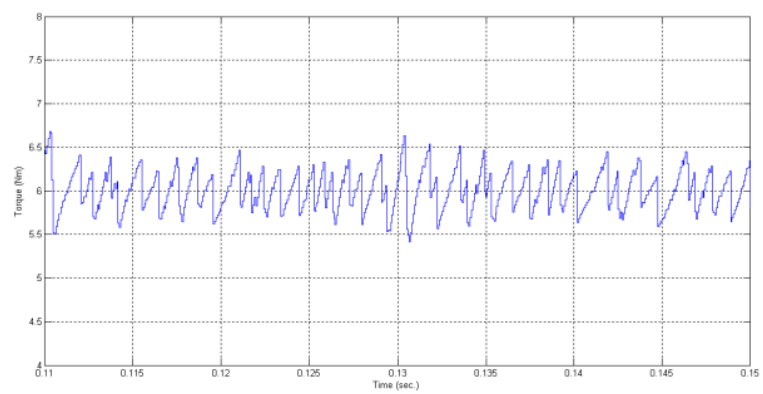

Fig. 12(a) Steady state torque for ST-DTC

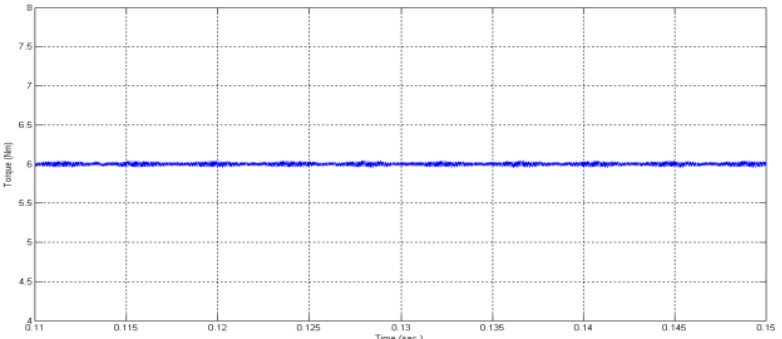

Fig. 12(b) Steady state torque for cascade structure of DTC-SVM

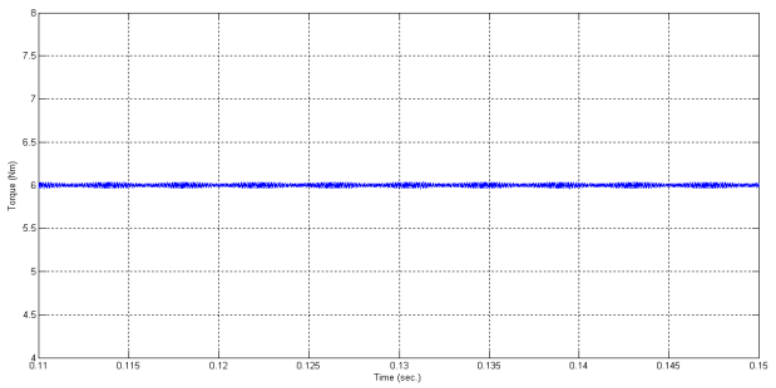

Fig. 12(c) Steady state torque for parallel structure of DTC-SVM

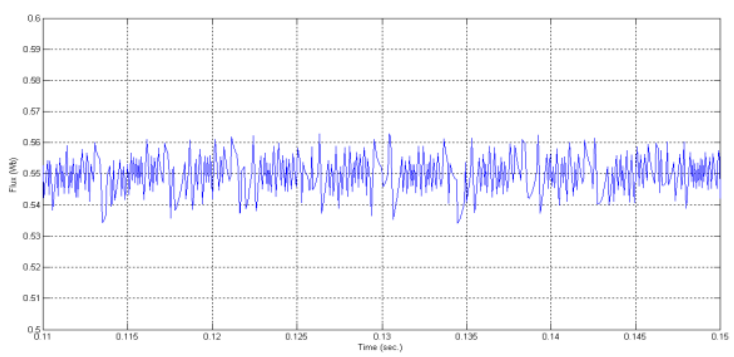

Fig. 13(a) Steady state flux linkage for ST-DTC

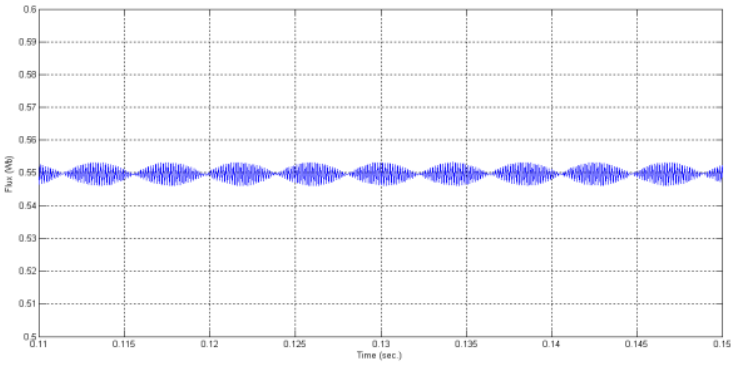

Fig. 13(b) Steady state flux linkage for cascade structure of DTC-SVM

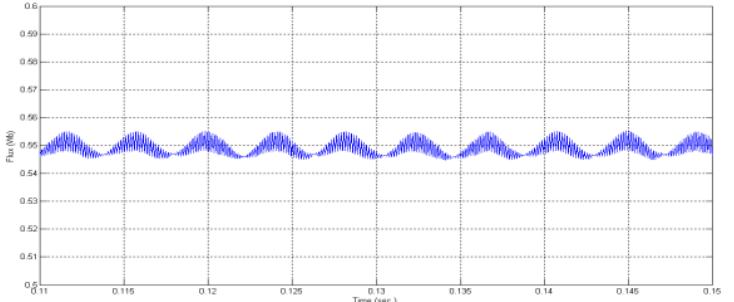

Fig. 13(c) Steady state flux linkage for parallel strcture of DTC-SVM

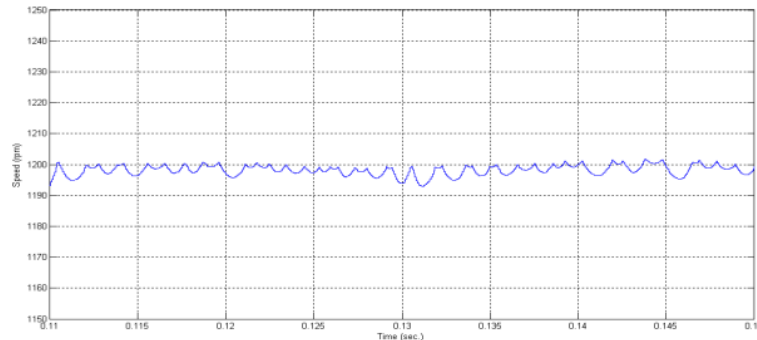

Fig. 14(a) Steady state speed for ST-DTC

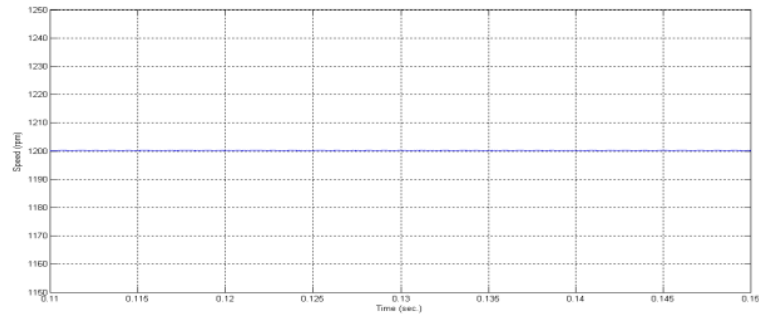

Fig. 14(b) Steady state speed for cascade structure of DTC-SVM

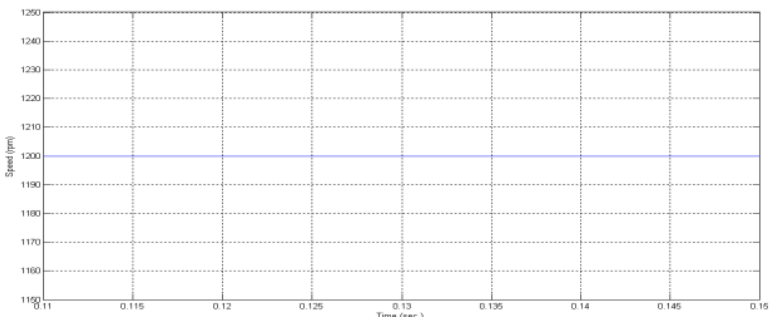

Fig. 14(c) Steady state speed for parallel structure of DTCSVM 


\section{International Advanced Research Journal in Science, Engineering and Technology}

Vol. 2, Issue 8, August 2015

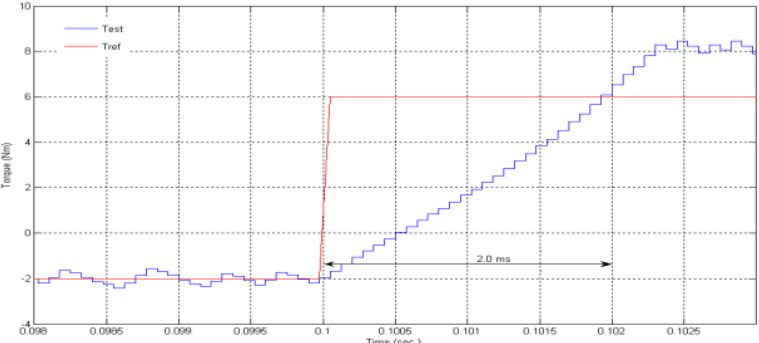

Fig. 15(a) Dynamic torque response for ST-DTC

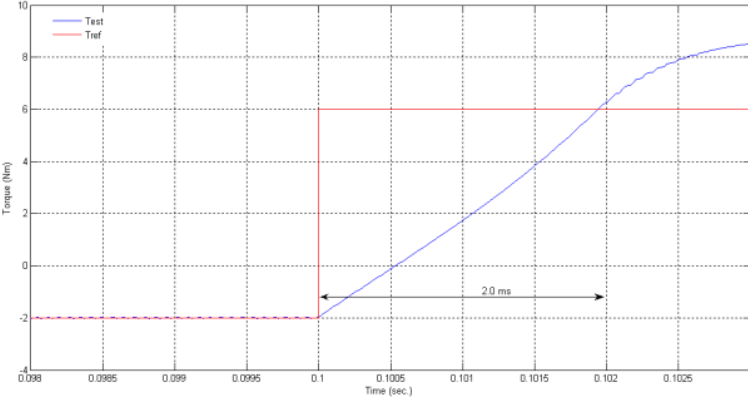

Fig. 15(b) Dynamic torque response for cascade structure of DTC-SVM

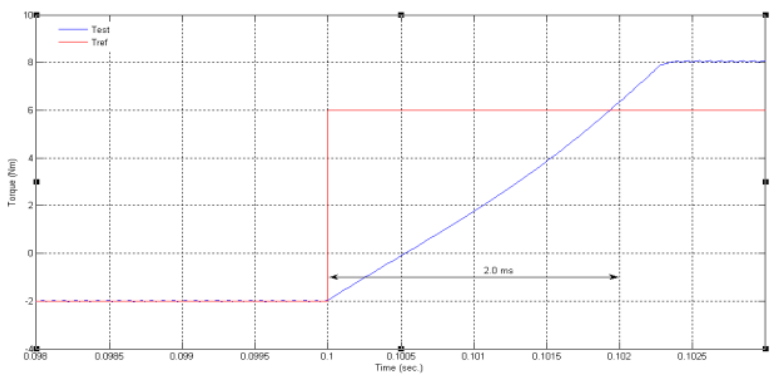

Fig. 15(c) Dynamic torque response for parallel structure of DTC-SVM

\section{CONCLUSION}

The primary contribution of this paper is the development, analysis and simulation verification of DTC for IPMSM drive. The classical ST-DTC has many advantages over vector control but it suffers from high ripples in torque and flux linkage and varying inverter switching frequency. The disadvantages of classical STDTC have been overcome by two different types of DTCSVM schemes. The simulation results show that the ripples in flux and torque are greatly reduced with fixed switching frequency in DTC-SVM schemes compared to classical ST-DTC

\section{APPENDIX C}
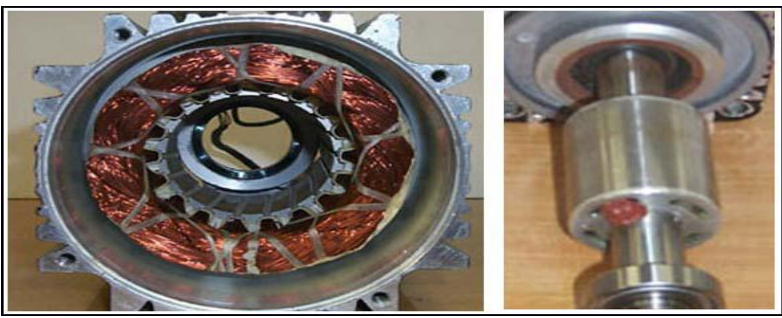

Fig.16 View of stator and rotor of an IPM synchronous motor

\section{REFERENCES}

1. T. Lixin, Z. Limin, M. F. Rahman, and Y. Hu, "A Novel Direct Torque Controlled Interior Permanent Magnet Synchronous Machine Drive With Low Ripple in Flux and Torque and Fixed Switching Frequency", Power Electronics, IEEE Transactions on vol. 19, pp. 346-354, 2004.

2. Jun Zhang, M.Faz Rahman, and Colin Grantham, "A New Scheme to Direct Torque Control of Interior Permanent Magnet Synchronous Machine Drives for Constant Inverter Switching Frequency and Low Torque Ripple", Power Electronics and Motion Control Conference, 2006, IPEMC'06 CES/IEEE 5th International vol. 3, Aug 2006 pages 1-5.

3. L.Zhong, M.F. Rahman, W. Y. Hu, and K.W. Lim, "Analysis of Direct Torque Control in Permanent Magnet Synchronous Motor Drives", Power Electronics, IEEE Transactions on, vol. 12, no.3, May 1997 pp.528-536.

4. K. Gulez, A. A. Adam, H. Pastaci, "Improving the Performance of Hysteresis Direct Torque Control of IPMSM Using Active Filter Topology", SADHANA-Academy Proc. in Engineering Sciences, Vol. 31, Part.3, June 2006 pp. 245-258.

5. Ying-Shieh Kung, Pin-Ging Huang, "High Performance Position Controller for PMSM Drives Based on TMS320F2812 DSP", Proceedings of the 2004 IEEE International Conference on Control Application, Volume: 1, 2-4 Sept. 2004, pp. 290-295

6. Z.-G. Wang, J.-X. Jin, Y.-G. Guo et al., "SVPWM Techniques and Applications in HTS PMSM Machines Control", JESTC, vol. 6, no. 2, pp. 191-197, 2008

7. I. Boldea, S.A. Nasar, "Electrical drives", CRC Press, 1999.

8. Peter Vas, "Sensorless Vector and Direct Torque Control", Oxford University Press 1998.

9. R.Krishnan, "Electric Motor Drives: Modeling, Analysis, and Control", Pearson Education, Inc. 2003.

10. P.C. Krause, O. Wasynczuk, S.D. Sudhoff, "Analysis of Electric Machinery”, IEEE Press, 1995. 